\title{
The Study of Long-term Energy-saving LED Airfield Lighting System
}

$$
\text { Yang Jianhong }{ }^{1} \text {,Li Lei }{ }^{2} \text {,Li Tuo }{ }^{3} \text {,Li Xingbo }{ }^{4}
$$

The Second Research Institute of CAAC, 17 South Section 2 ,2nd Ring Road, Chengdu City, Sichuan Province, China

17 South Section 2,2nd Ring Road, Chengdu City, Sichuan Province, China jasongm@163.com, lilei_1625@163.com,43247964@qq.com,1780858463@qq.com

Keywords: LED, lighting system, power supply system, sine wave regulator, energy saving Abstract. Based on the analysis of power consumption of the circuits, isolation transformers and secondary cables of traditional lighting systems, this paper proposes a long-term power efficient lighting system regarding LED airfield lamps, without modifying the topology of power circuit. New types of sine wave regulator and lamp controller are designed accordingly for this lighting system.

\section{Introduction}

Traditional airfield lighting systems are powered up by constant current regulators in which the output terminal of boosting transformer connects the main circuit cable, and connects multiple isolation transformers in lighting circuit. The secondary side of isolation transformers connects airfield lamps, halogen lamp or tungsten bromine lamp. Figure 1 shows the topology.

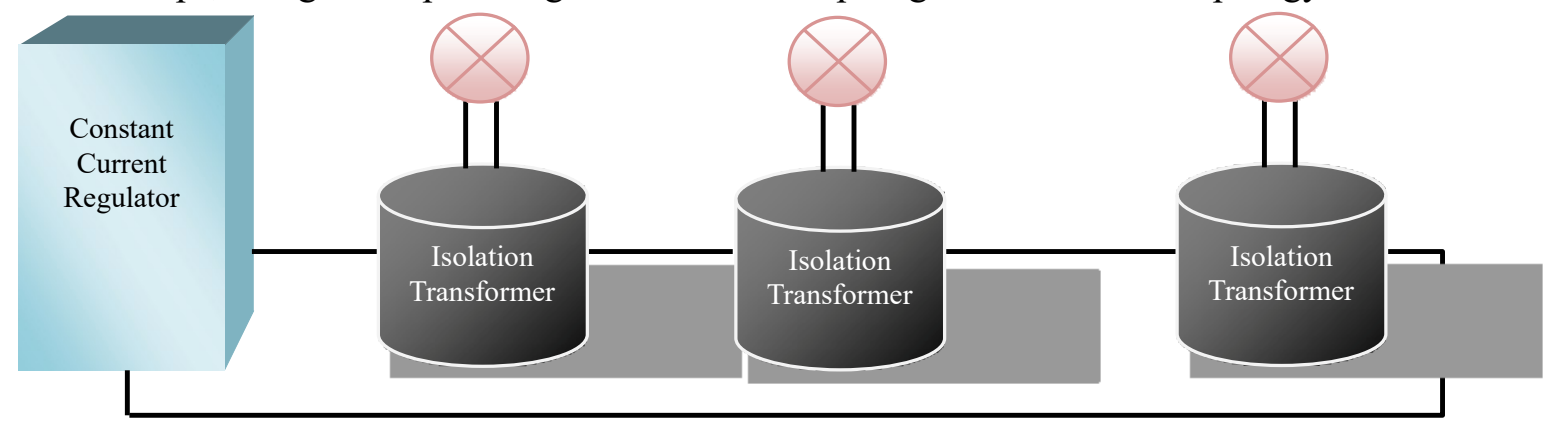

Figure 1. Topology of Traditional Airfield Lighting Systems

In the power supply circuit of traditional airfield lighting, the consumption of electrical energy is mainly composed of four parts: consumption of power of light source, the loss of main circuit cables, isolation transformers and secondary cable of lamps. Take the circuit composed by 100 taxiway sidelights (tungsten bromine lamp) as an example. The following is the analysis of consumption of airfield lighting system. For the convenience of estimation, the length of main circuit cable is $\mathrm{L}_{\text {main }}=10 \mathrm{~km}$, the length of secondary cable $\mathrm{L}_{\mathrm{sec}}=5000 \mathrm{~m}$, and each lamp uses $50 \mathrm{~W}$ of isolation transformer for power supply. The consumption of each part of circuit is estimated as below. 1) Power of Light Source

The power of a single taxiway sidelight with traditional halogen light source is $\mathrm{P}_{0}=50 \mathrm{~W}$, and the power consumed by circuit lamp is

$$
\mathrm{P}_{\text {lamp }}=\mathrm{N}^{*} \mathrm{P}_{0}=50 * 100=5000 \mathrm{~W} \text {. }
$$

\section{2) Loss of Main Circuit Cable}

When the temperature is $20^{\circ} \mathrm{C}$, the impedance of commonly used $6 \mathrm{KV}$ and $10 \mathrm{KV}$ airfield lighting exclusive cables with the sectional area of $6 \mathrm{~mm}^{2}$ is $\mathrm{R}_{0}=2.917 \Omega / \mathrm{km}$ 。If the regulator output current is $\mathrm{i}=6.6 \mathrm{~A}$, the loss of main circuit cable is

$$
\mathrm{P}_{\text {main }}=\mathrm{I}^{2} * \mathrm{R}_{0} * \mathrm{~L}_{\text {main }}=6.6 * 6.6 * 2.917 * 10=1271 \mathrm{~W} \text {. }
$$




\section{3) Loss of Isolation Transformers}

The loss of isolation transformers depends on its efficiency and load power. The commonly-used transformers in airports are $30 \mathrm{~W}, 50 \mathrm{~W}, 100 \mathrm{~W}$ and $200 \mathrm{~W}$ transformers. Considering the aging factor, the efficiency of $50 \mathrm{~W}$ isolation transformers is estimated as $\eta_{50}=0.75$. Thus the loss of $10050 \mathrm{~W}$ isolation transformers is

$$
\mathrm{P}_{\text {tran }}=\mathrm{N} * \mathrm{P}_{0} *\left(1-\eta_{50}\right)=100 * 50 *(1-0.75)=1250 \mathrm{~W} .
$$

\section{4) Loss of Lamp Secondary Cables}

If the unit loss of $2.5 \mathrm{~mm}^{2}$ lamp secondary cables is $\mathrm{P}^{\prime}=0.305 \mathrm{~W} / \mathrm{m}$ in $6.6 \mathrm{~A}$ current, the loss of secondary cable is

$$
\mathrm{P}_{\mathrm{sec}}=\mathrm{L}_{\mathrm{sec}} * \mathrm{P}^{\prime}=5000 * 0.305=1525 \mathrm{~W}
$$

In short, it can be concluded, from (2), (3) and (4), that the circuit loss of a traditional circuit powered by $50 \mathrm{~W}$ isolation transformer and composed of 100 taxiway sidelight is

$$
\mathrm{P}_{\text {circuit }}=\mathrm{P}_{\text {main }}+\mathrm{P}_{\text {tran }}+\mathrm{P}_{\mathrm{sec}}=1271+1250+1525=4046 \mathrm{~W}
$$

In formula (1), the consumption of circuit light source is $\mathrm{P}_{\text {lamp }}=5000 \mathrm{~W}$, indicating severe circuit power consumption which amounts to $80.92 \%$ of the power consumption of circuit lamp.

At present, LED airfield lamps have replaced traditional airfield lamps in some domestic airports in China, but power efficiency is not satisfying. Xi' an Xianyang Airport has replaced partial runway edge lights and taxiway central line lights with LED airfield lamps of ADB, and the 50w halogen lamp of taxiway edge lights is replaced by $1 \mathrm{w}$ LED lamp beads, but its energy conservation percentage is less than $40 \%$.

The main reason is that, using LED airfield lamp on traditional circuit greatly decreases the power consumption of lamps, but the power loss of the circuit does not decrease accordingly. For the entire airfield lighting system, the system power consumption reduces at best a half, which is far from adequate to demonstrate the energy saving effect. Therefore, setting up a long-term energy saving LED airfield lighting system will help airports to achieve the goal of energy conservation.

\section{Power Supply System Based on LED Airfield Lighting System}

The airfield lighting system is crucial to the safe launching and landing of aircrafts. With the established requirement of ICAO, FAA and domestic regulations concerned, the topology structure of airfield lighting system can hardly be modified. As the nature of LED light source is low voltage DC power supplied, to meet international criteria of airfield lighting system, a lamp controller needs to be added to the LED airfield lights to adjust the light intensity. Figure 2 illustrates the topology structure of LED airfield lighting system before it is modified: 


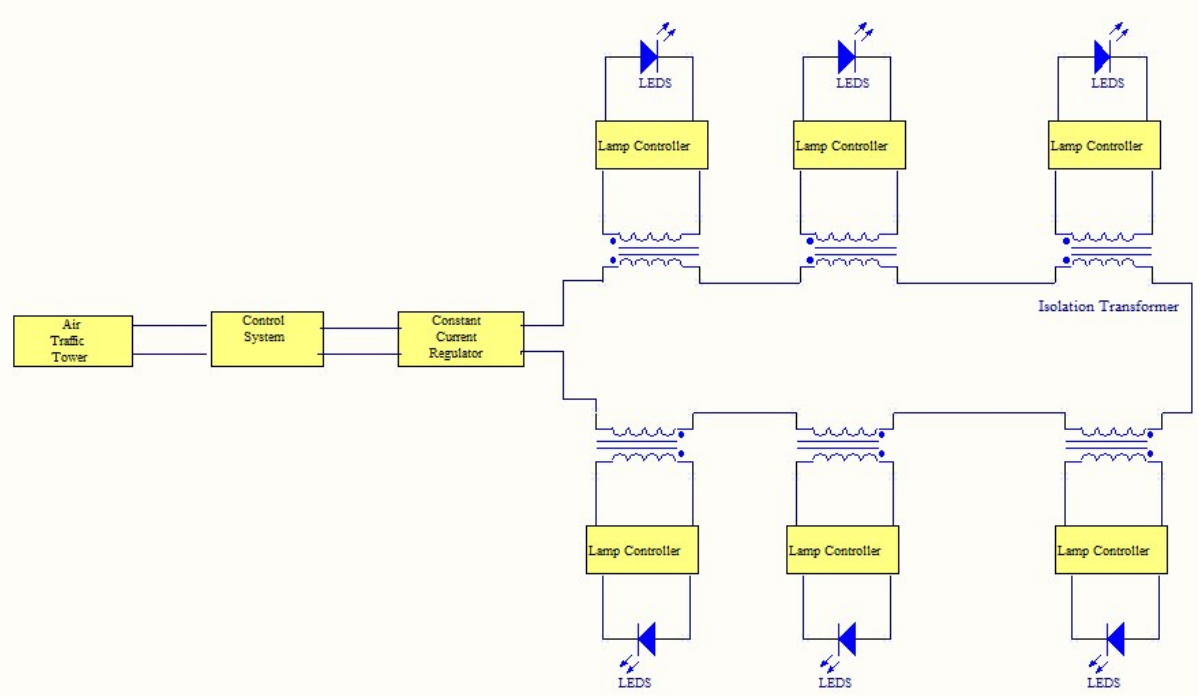

Figure 2. Topology of LED Airfield Lighting System

The luminous efficiency of LED is much higher than that of tungsten bromine lamps and halogen lamps. The luminous efficiency of white light LED amounts to as high as 150 lumens/w, while the luminous efficiency of colour LED reaches 80 lumens/w. Through theoretical calculation, software modelling as well as lamp verification, it proves that LED airfield lights do not need to be driven by the current of 6.6A. Even for the 20000CD approach light, the $2 \mathrm{~A}$ current is sufficient for the criteria. For the taxiway edge light with the minimum intensity requirement, driving a $1 \mathrm{w}$ blue LED only needs a current of $300 \mathrm{~mA}$.

The regulator (CCR) of airfield lighting system is in fact an AC constant current power supply whose output current, output frequency and phase are key parameters. Considering the level of difficulty and accuracy of parameter detection, the output frequency is more suitable to be used as the parameter of light intensity levels. Thus, a new type of LED airfield lighting power system can be designed as follows: with different intensity requirements, when the regulator outputs different constant current, it at the same time outputs sine wave of different frequencies between $1 \mathrm{~Hz}$ and $2 \mathrm{~Hz}$. When the different frequencies are detected, the LED airfield lights adjust the driving current to ensure the output is equivalent to corresponding intensity. $1 \mathrm{~Hz}$ frequency interval is adopted, and the maximum circuit current is $2 \mathrm{~A}$. The relationship of intensity levels and regulator output of the new type of airfield lighting power system is shown in Table 1.

Table 1. Intensity Levels Specified by New Power System of Airfield Lighting

\begin{tabular}{|c|c|c|}
\hline intensity level & output frequency & output currency \\
\hline level 1 & 48 & $0.5 \mathrm{~A}$ \\
\hline level 2 & 49 & $0.5 \mathrm{~A}$ \\
\hline level 3 & 50 & $0.5 \mathrm{~A}$ \\
\hline level 4 & 51 & $1 \mathrm{~A}$ \\
\hline level 5 & 52 & $2 \mathrm{~A}$ \\
\hline
\end{tabular}

The new power system of airfield lighting system is able to guarantee that while assuring the light intensity requirement at each level of intensity, the circuit loss is less than the loss powered by the 2.8A $\sim 6.6 \mathrm{~A}$, without adding extra transmission links for intensity level information, facilitating the modification of traditional airfield lighting systems. Take the circuit of 100 taxiway edge lamps as 
an example, the energy saving effect of new power system is shown in Table 2 and Table 3 . In the tables, the isolation transformer of LED airfield lighting is $30 \mathrm{w}$.

Table 2. The Calculation Table for 100 Lamp Single Circuit Loss

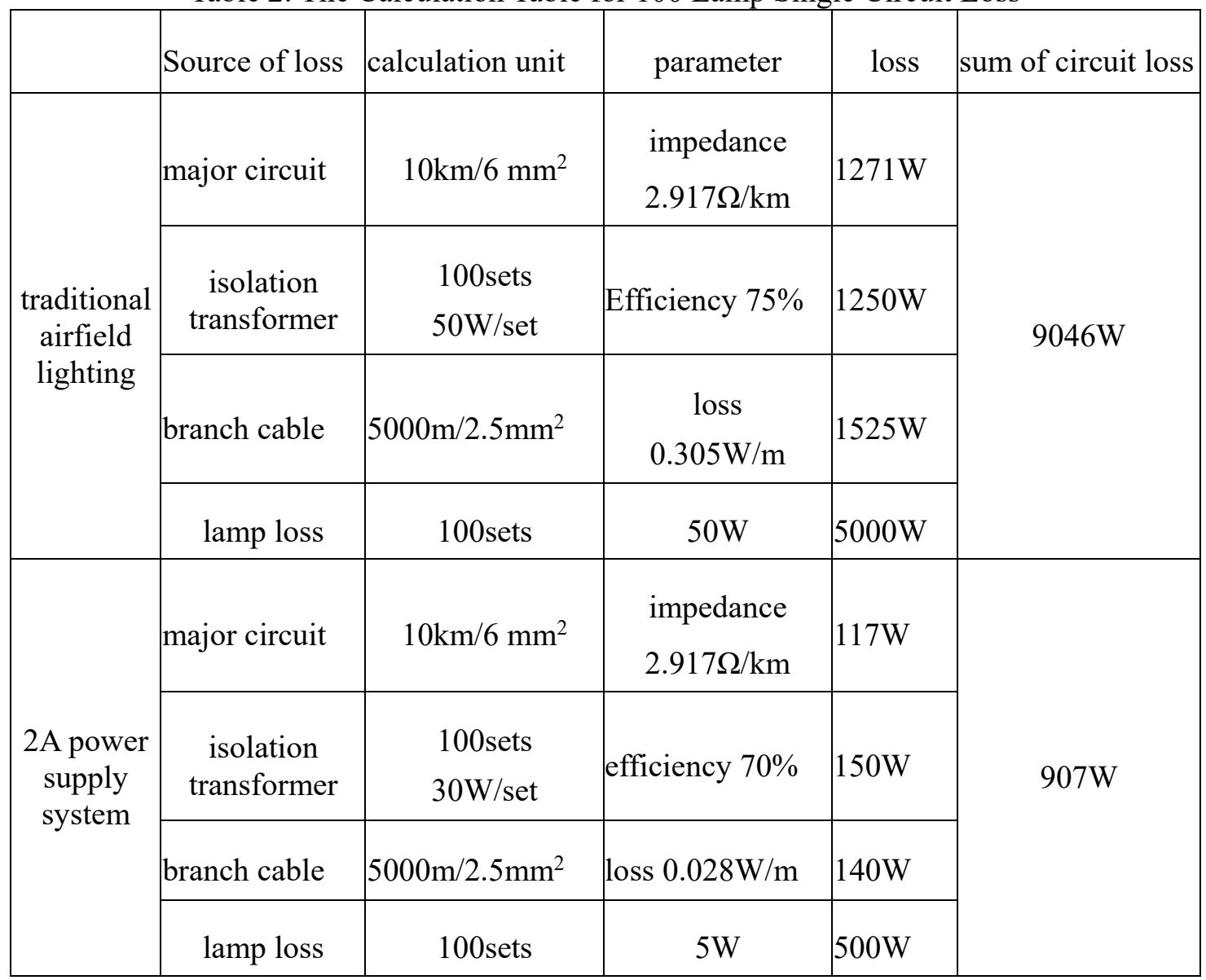

Table 3. Statistical Table for 100 Lamp Single Circuit Energy Saving

\begin{tabular}{|l|l|l|l|}
\hline source of loss & $\begin{array}{l}\text { traditional airfield } \\
\text { lighting circuit }\end{array}$ & $\begin{array}{l}2 \mathrm{~A} \quad \text { power } \\
\text { system }\end{array}$ & $\begin{array}{l}\text { energy saving } \\
\text { percentage }\end{array}$ \\
\hline major circuit & $1271 \mathrm{~W}$ & $117 \mathrm{~W}$ & $90.80 \%$ \\
\hline $\begin{array}{l}\text { isolation } \\
\text { transformer }\end{array}$ & $1250 \mathrm{~W}$ & $150 \mathrm{~W}$ & $88.00 \%$ \\
\hline branch cable & $1525 \mathrm{~W}$ & $140 \mathrm{~W}$ & $90.82 \%$ \\
\hline lamp loss & $5000 \mathrm{~W}$ & $500 \mathrm{~W}$ & $90 \%$ \\
\hline sum circuit loss & $9046 \mathrm{~W}$ & $907 \mathrm{~W}$ & $89.97 \%$ \\
\hline
\end{tabular}

Table 3 indicates that, using the new type of power system, the circuit of LED taxiway edge light is able to save energy by $84.5 \%$ in comparison with traditional circuit. Key Technologies

Sine wave Regulator

Traditional regulators are set to have five levels of output whose frequency is $50 \mathrm{~Hz}$ at all levels and the output current are respectively $2.8 \mathrm{~A}, 3.4 \mathrm{~A}, 4.1 \mathrm{~A}, 5.2 \mathrm{~A}$ and $6.6 \mathrm{~A}$. Hence, to adapt to the new power system, it is important to develop a new type of regulator. 
Differing from traditional regulators, apart from maintaining the constant output feature of traditional regulators, the new regulators also possess the function of frequency-converted output. The basic principle is to convert $220 \mathrm{v} A C$ via $\mathrm{AC} \rightarrow \mathrm{DC} \rightarrow \mathrm{AC}$, and to generate clean sine wave current with adjustable output frequency and amplitude within a certain range. By regulating the output sine wave frequencies, the regulators send intensity level order to control the intensity levels of LED lights and, in the meanwhile, modify output current to fit in with the current, improving power factor demanded by corresponding intensity level, eliminating unnecessary power consumption and saving energy.

The regulator employs the most advanced IGBT inverter output technology in the world, which uses the high performance precision power supply controlled by advanced micro processors. It has the functionalities of over-current protection, short-circuit protection, over-voltage protection, under-voltage protection and overload protection, as well as fault alarm display, ensuring the safety of the regulator. It is featured by strong load adaptability, good output waveform and user interface. Small and light, it is easy to operate.

The regulator is used for inductive load, whose maximum output current is $7 \mathrm{~A}$, the highest output voltage is $4500 \mathrm{~V}$, and the output frequency $45 \mathrm{~Hz}-60 \mathrm{~Hz}$. The block diagram is illustrated in Figure 3.

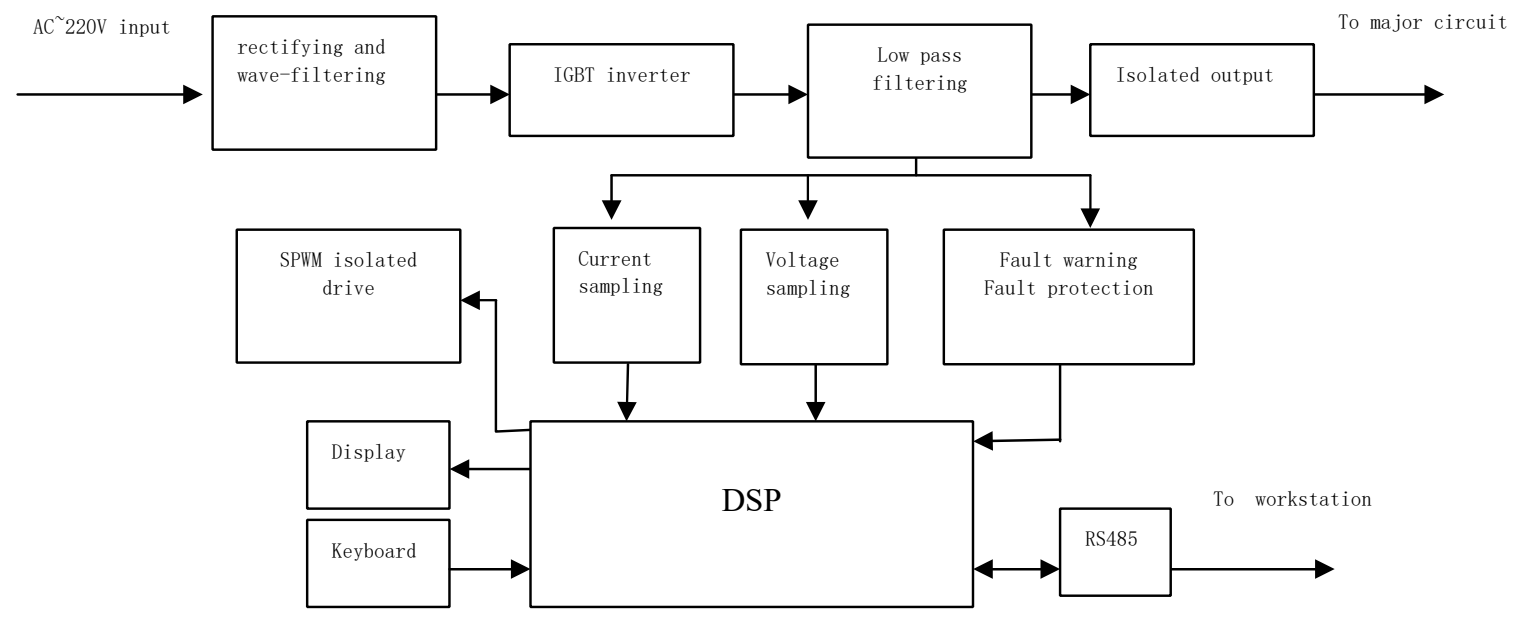

Figure 3. Block Diagram of The Regulator Principles

\section{Lamp Controller}

The lamp controller is composed of surge protection, current detection, frequency detection, rectifier filter, MCU, and LED driver. The input of lamp controller is connected to the output of isolation transformers, and carries out the $\mathrm{AC} / \mathrm{DC}$ transformation at the end of surge protection device. The DC voltage after rectifier filtering provides, on one hand, the power for micro processors via DC/DC voltage transformation; on the other hand, it provides LED drivers with DC driving power. MCU first detects from the isolation transformer the sine wave frequency or the current effective value output by the generator, and then generates regulator signal required by the intensity level corresponding to this frequency or current value. The signal output to the control terminal of LED driving circuit, controls the current flowing by LED, and eventually controls the LED intensity. The schematic diagram of lamp controller is shown in Figure 4. 


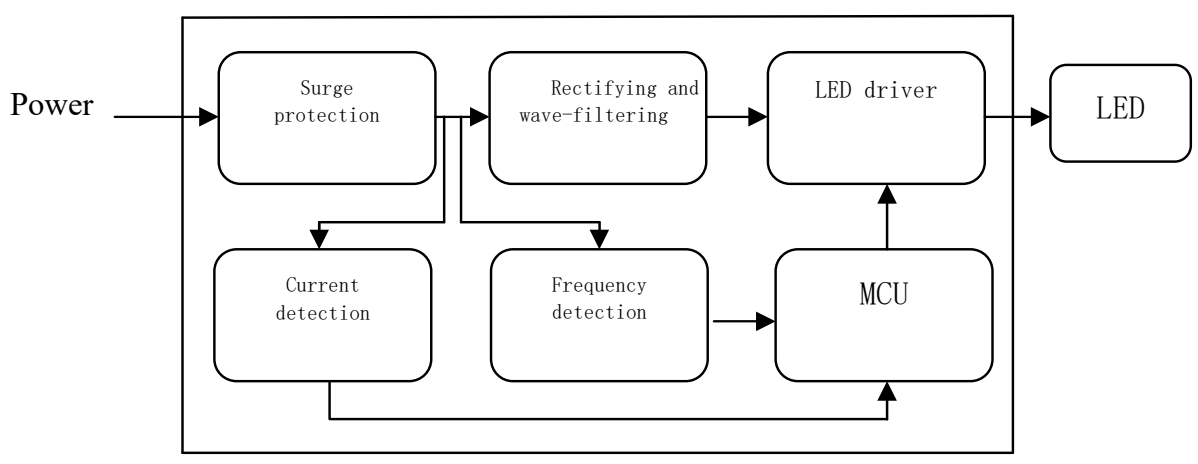

Figure 4. Block Diagram of The Lamp Controller Conclusion

Through analysing the power consumption of traditional airfield lighting power systems, this paper proposes a long-term energy-saving airfield lighting system which, without changing the topology structure of traditional airfield lamps, combines the feature of small LED current and adopts the output frequency of regulators as lighting level. This airfield lighting system designs a SPWMbased sine wave inverter constant current regulator, as well as a lamp driver that is able to implement 5 levels of dimming based on different power frequencies or current. The regulator and lamp driver are applicable to LED airfield lighting systems for the purpose of long term energy saving.

\section{References}

[1] Shen Hengde constant current aviation engineering and maintenance [J]. light device for navigation lights, 1999 (6): 19-19.

[2] Li Xiaoming. Design of the constant current light modulator of the DSP based on the [D].. Dalian Jiaotong University, 2008

[3] Jiang Xiejun. Analysis of [J]. production of electronic power supply and dimming system for navigation lights system, 2013 (10).

[4] Cao Zhijian. A preliminary discussion on the selection of [J]. airport construction for the lighting system of the navigation aids, 2014 (4): 20-21.

[5] Xuqiu. A new type of energy-saving technology of airfield lighting system in the application of $[\mathrm{J}]$. intelligent electrical building technology at the airport, 2013 (3): 50-53.

[6] manifold. A new type of light level setting device for LED navigation lights: CN201657433U[P]., CN 2010

[7] Miao Weiguo, Yi dragon, Liu Guodong. The application of [J]. LED at the airport in mechanical manufacture and automation, 2007, 36 (3): 128-129.

[8] Jiang Xiaobo, Zhou Xiaoli, Chen Yuyang, et al. LED taxiway centerline light driving circuit design of [C]// China Association annual meeting 2010.

[9] Zhu Hong. Application of LED technology in the lighting system of navigation aids [J]. airport construction, 2015 (2): 38-38.

[10] Tang Yongsheng, Yang Jianhong, Li Lei, et al. Research and development of LED based lighting system for the [J]. civil aviation science and technology, 2009 (4): 129-132.

[11]ROM. [C]// 2004 national semiconductor lighting technology and Application Seminar in aviation and airport lighting systems LED 2004. 